Journal of Chromatography, 310 (1984) 159-166

Biomedical Applications

Elsevier Science Publishers B.V., Amsterdam - Printed in The Netherlands

CHROMBIO. 2188

\title{
DETERMINATION OF MISONIDAZOLE AND \\ DESMETHYLMISONIDAZOLE IN PLASMA BY HIGH-PERFORMANCE LIQUID CHROMATOGRAPHY WITH REDUCTIVE ELECTROCHEMICAL DETECTION
}

\author{
P.G. MEERING, R.A. BAUMANN, J.J. ZIJP and R.A.A. MAES* \\ Centre for Human Toxicology, State University of Utrecht, Vondellaan 14, $3521 \mathrm{GE}$ \\ Utrecht (The Netherlands)
}

(First received February 9 th, 1984 ; revised manuscript received April 18th, 1984)

\section{SUMMARY}

A reversed-phase high-performance liquid chromatographic method with reductive mode electrochemical detection was developed for the determination of misonidazole and desmethylmisonidazole in plasma. A thin-layer amperometric detector with glassy carbon working electrode was used to detect the nitroimidazoles at a potential of $-0.60 \mathrm{~V}$. The calibration curves were linear. The within-day and day-to-day coefficients of variation were below $3 \%$ for plasma misonidazole concentrations of $6-60 \mathrm{mg} / \mathrm{l}$ and $1-15 \mathrm{mg} / \mathrm{l}$ for desmethylmisonidazole. Electrochemical detection limits were between 2 and $4 \mathrm{pg}$, which is about 10-20 times lower than that obtained by detection at $323 \mathrm{~nm}$. Limits of quantitation of the nitroimidazoles in plasma were in the order of $1-2 \mu \mathrm{g} / 1$. Under the described conditions other nitroimidazoles and nitro compounds can also be detected with ultimate sensitivity by reductive mode electrochemical detection.

\section{INTRODUCTION}

Misonidazole, 1-(2-nitroimidazol-1-yl)-3-methoxypropan-2-ol, has been shown to increase the sensitivity of hypoxic cells to the lethal effects of ionizing radiation $[1,2]$. Hypoxic cells present in animal and human tumours $[3,4]$ are more resistant to radiotherapy than oxygenated cells $[5,6]$, and misonidazole has been widely investigated as a radiosensitizing drug in the radiation therapy of tumours $[1,2,7-10]$. However, several toxic effects have been observed after the administration of misonidazole to man $[7,9-12]$, Determination of misonidazole and its metabolites in biological materials might help to determine a therapeutic range that is non-toxic.

Various methods of determination of misonidazole and its metabolites have 
been reported. Spectrophotometric $[9,13]$ and polarographic $[11,13]$ procedures used in animal and human studies do not differentiate between misonidazole and its major metabolite desmethylmisonidazole [14]. Polarographic [15, 16] and spectrophotometric [15] procedures with an extra thin-layer chromatography (TLC) separation step and gas-liquid chromatographic (GLC) methods with electron-capture detection $[14,15]$ are selective, but these methods are too lengthy for routine use. Normal-phase $[14,17]$ and reversed-phase [18] TLC techniques, although selective, lack sensitivity. High-performance liquid chromatographic (HPLC) methods with ultraviolet (UV) detection [19-21] are available for the separate quantitation of misonidazole and desmethylmisonidazole. However, HPLC technology with UV detection is not able to detect the amine metabolite of misonidazole [14], which does not have a typical UV spectrum [22]. Because metabolic alteration of misonidazole at the nitro group might be an important factor for the development of the neurotoxic [23], cytotoxic [24] and mutagenic [25] effects of the drug, it was felt necessary to develop more specific methodology.

This paper describes a fast, selective and sensitive procedure for the determination of misonidazole and desmethylmisonidazole in plasma by means of liquid chromatography with reductive electrochemical detection.

\section{EXPERIMENTAL}

\section{Chemicals and reagents}

Misonidazole, 1-(2-nitroimidazol-1-yl)-3-methoxypropan-2-ol (Ro 07-0582), desmethylmisonidazole, 1-(2-nitroimidazol-1-yl)-2,3-propandiol (Ro 05-9963), and the internal standard, 1-(2-nitroimidazol-1-yl)-3-ethoxypropan-2-ol (Ro 07-913), were kindly provided by Hoffmann-La Roche (Mijdrecht, The Netherlands). Metronidazole and dimetridazole were donated by RhônePoulene (Amstelveen, The Netherlands). Tinidazole was a gift from Pfizer (Rotterdam, The Netherlands). Nimorazole was provided by Farmitalia Carlo Erba (Brussels, Belgium). Nitrofurantoin and 2-nitroimidazole were purchased from Ega-Chemie (Steinheim, F.R.G.). Analytical grade acetic acid, sodium acetate, ethylenediamine tetraacetic acid disodium salt $\left(\mathrm{Na}_{2}\right.$ EDTA) and HPLC grade methanol were obtained from Merck (Darmstadt, F.R.G.). Water was twice distilled in glass.

\section{Apparatus}

The high-performance liquid chromatograph consisted of a Model 6000A pump (Waters Assoc., Milford, MA, U.S.A.), a Model 7125 syringe loading sample injector with 50- $\mu 1$ sample loop (Rheodyne, Berkeley, CA, U.S.A.) and a Model LC-4 amperometric detector (Bioanalytical Systems, West Lafayette, IN, U.S.A.). All tubings were constructed of stainless steel. A Bourdon tube pulse damper filled with nitrogen gas was fixed off-line in a T-union between pump and injector. Separations were performed on an octadecylsilane reversed-phase column ( $\mu$ Bondapak $\mathrm{C}_{18}, 30 \mathrm{~cm} \times 3.9 \mathrm{~mm}$, mean particle size $10 \mu \mathrm{m}$ ) (Waters Assoc.). The amperometric detector used a TL-5 thin-layer detector cell with a glassy carbon working electrode.

A Model 970 A variable-wavelength UV-VIS detector (Tracor Instruments, 
Austin, TX, U.S.A.) was also used in some experiments. Detector output was registered by a 3353 A Laboratory Automation System (Hewlett-Packard, Avondale, PA, U.S.A.). Other equipment included a Vortex type mixer, reciprocating shaker, centrifuge and $100 \times 16.25 \mathrm{~mm}$ disposable glass tubes (Renes, Zeist, The Netherlands) with polypropylene caps (Greiner, Alphen a/d Rijn, The Netherlands).

\section{Chromatographic conditions and instrumental settings}

Chromatography was performed at ambient temperature. The mobile phase, which consisted of a mixture $(20: 80, \mathrm{v} / \mathrm{v})$ of methanol and $0.15 \mathrm{M}$ acetate buffer ( $\mathrm{pH} 4.0$ ) containing $1.25 \mathrm{mM} \mathrm{Na} \mathrm{N}_{2}$ EDTA, was continuously stirred and delivered isocratically at a constant flow-rate of $1.5 \mathrm{ml} / \mathrm{min}$ and a pressure of about $11.0 \mathrm{MPa}$. The mobile phase was deaerated by passing nitrogen via a $2-\mu \mathrm{m}$ mobile phase filter through the solution at a flow-rate of $20 \mathrm{ml} / \mathrm{min}$. The sample solution was also deaerated before injection by passing nitrogen through the solution via a Pasteur pipette for about $7 \mathrm{~min}$ at a flow-rate of about 20 $\mathrm{ml} / \mathrm{min}$.

The column effluent was monitored at a working electrode potential of $-0.60 \mathrm{~V}$ versus the $\mathrm{Ag} / \mathrm{AgCl}$ reference electrode. Further instrumental settings of the electrochemical detector were a sensitivity of the controller output of 50 or $100 \mathrm{nA}$ full scale deflection and a time constant of $2 \mathrm{sec}$ unless otherwise stated. The electrochemical detector output was rccorded at $10 \mathrm{mV}$ with a chart speed of $20 \mathrm{~cm} / \mathrm{h}$. Instrumental settings of the UV detector were a detection wavelength of $323 \mathrm{~nm}$ and a detection sensitivity of 0.005 absorbance unit full scale deflection (a.u.f.s.). The UV detector output was recorded at $1 \mathrm{mV}$.

\section{Standard solutions}

A methanolic standard solution containing $6.3 \mathrm{mg} / \mathrm{l}$ of the internal standard and an aqueous additional buffer solution containing $0.16 \mathrm{M}$ acetate buffer $\mathrm{pH}$ 4.0 and $1.33 \mathrm{mM} \mathrm{Na} \mathrm{NaDTA}_{2}$ were prepared. A standard solution in mobile phase was made, containing desmethylmisonidazole, misonidazole and internal standard at respective concentrations of 75,290 and $1190 \mu \mathrm{g} / \mathrm{l}$. Five plasma standards were prepared, containing misonidazole in the range $6-60 \mathrm{mg} / \mathrm{l}$ as well as desmethylmisonidazole in the range $1-15 \mathrm{mg} / \mathrm{l}$. Aliquots of $1 \mathrm{ml}$ of the plasma standards were stored frozen at $-20^{\circ} \mathrm{C}$ until analysis.

\section{Precision, recovery and linearity}

Precision, recovery and linearity of the described method were determined using the five plasma standards containing both misonidazole and desmethylmisonidazole.

Within-day precision was established by processing ten aliquots of each plasma standard and day-to-day precision was determined by processing one aliquot of a plasma standard on each of ten days. Precision was expressed as coefficient of variation of the peak area ratio of misonidazole or desmethylmisonidazole to the internal standard. Recovery data were the means of four determinations at each concentration. Linearity of the calibration curves was studied with one aliquot of each plasma standard. 


\section{Procedure}

Add $4 \mathrm{ml}$ of the methanolic internal standard solution to $1 \mathrm{ml}$ of plasma in a stoppered glass tube. Vortex the tube for $10 \mathrm{sec}$, extract for $5 \mathrm{~min}$ on a reciprocating shaker and centrifuge at $2000 \mathrm{~g}$ for $10 \mathrm{~min}$. After centrifugation transfer $1 \mathrm{ml}$ of the supernatant to a second tube, add $3 \mathrm{ml}$ of additional buffer solution, mix and deoxygenate the solution with nitrogen. Fill the sample loop completely by suction and inject the deoxygenated solution once.

\section{Quantitation}

Plasma samples were processed according to the described procedure. Concentrations of misonidazole and desmethylmisonidazole in plasma samples were always calculated from calibration curves obtained after analysis of the five plasma standards. For both drugs calibration curves were constructed by plotting peak area ratio of the drug to the internal standard versus drug concentration in plasma and finding the best fitting line after least-squares linear regression analysis.

\section{RESULTS AND DISCUSSION}

\section{Chromatographic system}

Chromatographic systems consisting of an octadecylsilane reversed-phase column and a mobile phase of methanol-water $(20: 80, v / v)$ have shown a good separation between the nitroimidazoles $[19,20]$. As the electrochemical reduction of the aromatic nitro group proceeds more easily at lower $\mathrm{pH}$ [26], the mobile phase should preferably be acid. A methanol-acetate buffer $(\mathrm{pH}$ $4.0)(20: 80, \mathrm{v} / \mathrm{v})$ with a buffer acetate concentration of $0.15 \mathrm{M}$ gave a good separation and an acceptable compromise between an adequate detector response and a low background current. Addition of $0.001 \mathrm{M} \mathrm{Na}_{2}$ EDT A to the mobile phase reduced noise and baseline drift of the detector signal. This may be due to complexation of traces of metal ions, which are easily reduced at the glassy carbon electrode. Chromatograms of a plasma blank (A), plasma standard (B) and a standard solution in mobile phase (C) are shown in Fig. 1.

\section{Removal of oxygen}

For optimum performance of the electrochemical detector in the reductive mode oxygen should be removed from the mobile phase and from the injected solution [27]. The described method of deoxygenation with nitrogen, which was presaturated with mobile phase, prevented the appearance of an interfering oxygen peak with a retention time of 4.2 min almost completely. Background currents normally ranged between 10 and $20 \mathrm{nA}$.

\section{Electrochemical detection}

A glassy carbon electrode was chosen as a working electrode because of its known chemical resistance to organic solvents used in reversed-phase liquid chromatography, its large overpotential of oxygen, its mechanical stability and its simple repolishing procedure. The voltammetric behaviour of the three nitroimidazoles at the glassy carbon electrode was studied by obtaining multiple voltammograms of the drugs under the conditions described. At 


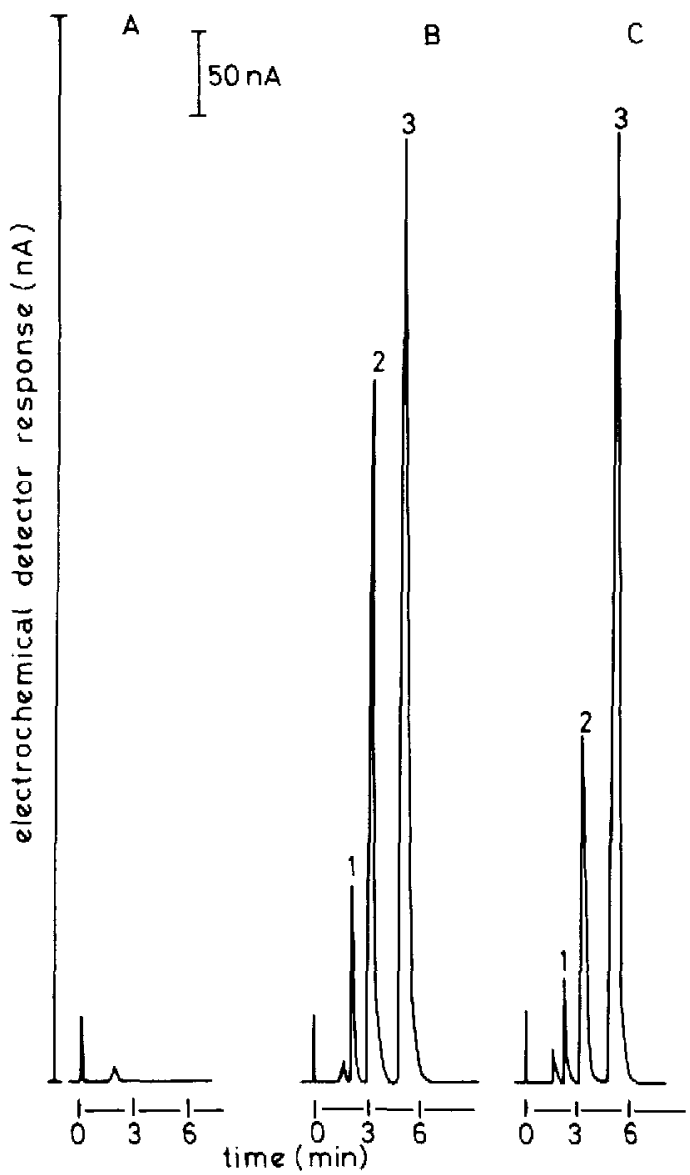

Fig. 1. Chromatograms of (A) blank plasma, (B) plasma standard containing $3.1 \mathrm{mg} / \mathrm{l}$ desmethylmisonidazole and $12.4 \mathrm{mg} / \mathrm{l}$ misonidazole, and (C) standard solution in mobile phase containing $75 \mu \mathrm{g} / 1$ desmethylmisonidazole, $290 \mu \mathrm{g} / \mathrm{l}$ misonidazole and $1190 \mu \mathrm{g} / \mathrm{l}$ internal standard. Peaks: $1=$ desmethylmisonidazole $\left(t_{R}=2.5 \mathrm{~min}\right) ; 2=$ misonidazole $\left(t_{R}=\right.$ $3.7 \mathrm{~min}) ; 3=$ internal standard $\left(t_{R}=5.5 \mathrm{~min}\right) . t_{R}=$ retention time. Injection volume: $50 \mu 1$.

each potential desmethylmisonidazole, misonidazole and internal standard were injected three times at respective amounts of 536, 542 and $488 \mathrm{pmol}$ and peak areas were measured. The hydrodynamic voltammograms (Fig, 2) demonstrate a very similar voltammetric behaviour of the three nitroimidazoles showing only one reductive wave. Hydrodynamic voltammograms of the nitroimidazoles were made in the potential range of 0 to $-0.9 \mathrm{~V}$, because sudden changes in detector sensitivity and non-reproducible voltammetric behaviour were noticed at working electrode potentials below $-0.9 \mathrm{~V}$. The choice of a detector potential of $-0.60 \mathrm{~V}$ seemed to be a good compromise between an adequate current response to nitroimidazoles and low background current.

\section{Precision, recovery and linearity}

Precision at the studied concentrations was good with coefficients of variation of $0.5-1.8 \%$ for the within-day precision and $1.9-3.1 \%$ for the dayto-day precision. The recoveries of $98.8-99.7 \%$ found for misonidazole and 

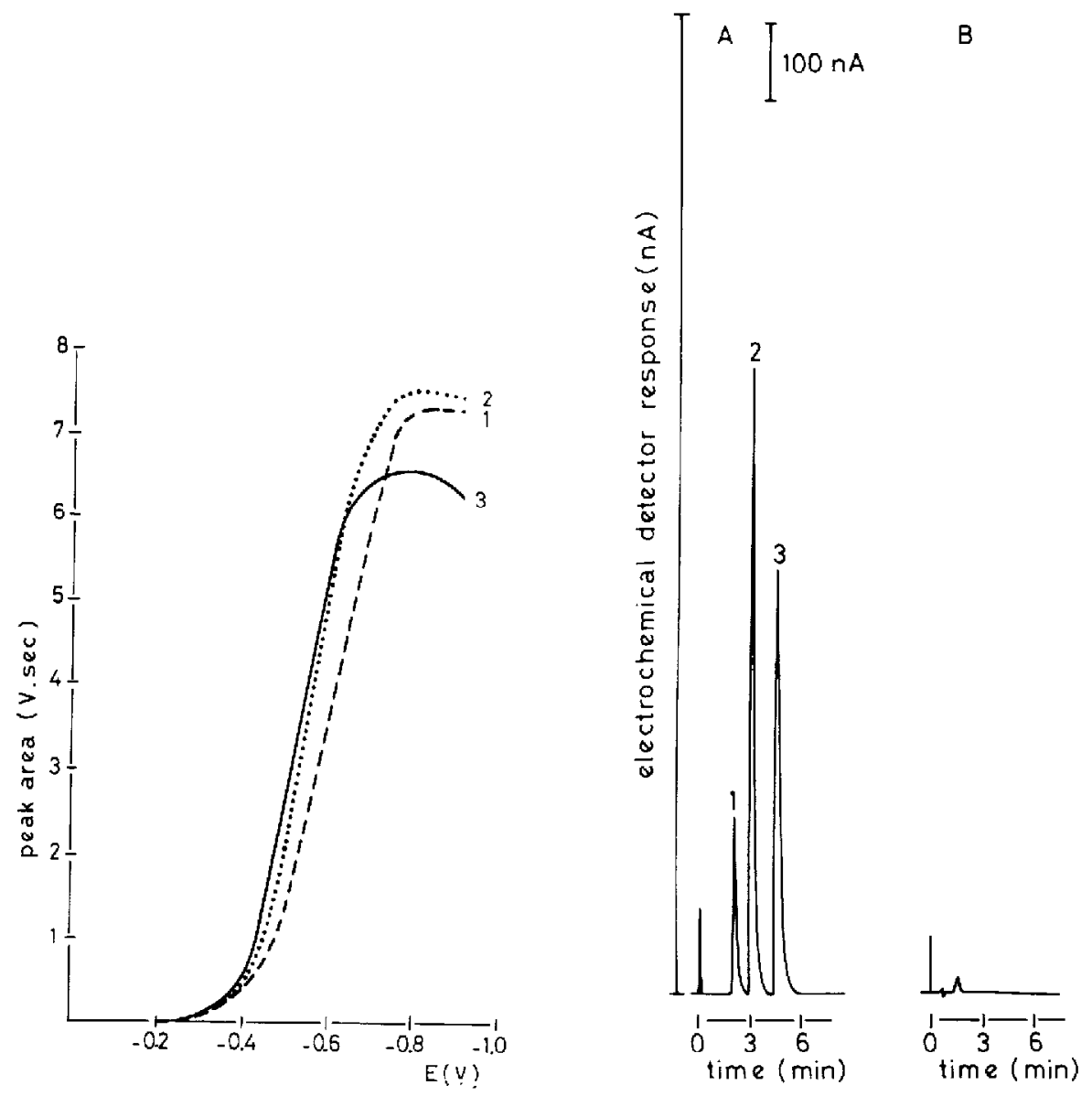

Fig. 2. Peak area-potential curves for desmethylmisonidazole (1), misonidazole (2) and internal standard (3).

Fig. 3. Chromatograms of a plasma sample of a patient $24 \mathrm{~h}$ after oral intake of $2.85 \mathrm{~g} / \mathrm{m}^{2}$ misonidazole (A) and of the control plasma sample before drug intake (B). Concentrations of desmethylmisonidazole and misonidazole were $6.8 \mathrm{mg} / \mathrm{l}$ and $27.5 \mathrm{mg} / 1$, respectively. Injection volume: $50 \mu \mathrm{l}$. Peaks: $1=$ desmethylmisonidazole; $2=$ misonidazole; $3=$ internal standard.

97.8-99.0\% obtained for desmethylmisonidazole indicate a complete recovery of both nitroimidazoles from plasma. Calibration curves constructed from the five plasma standards demonstrated good linearity. Equations of the linear regression lines of typical calibration curves are for desmethylmisonidazole $Y=$ $0.034 X+0.005(r=0.9999)$ and for misonidazole $Y=0.037 X+0.062(r=$ 0.9997 ), where $Y$ is the peak area ratio of drug to internal standard, $X$ is the plasma drug concentration in $\mathrm{mg} / \mathrm{l}$ and $r$ is the correlation coefficient.

\section{Sensitivity and detection limit}

Allowing a signal-to-noise ratio of 2 and measuring peak heights the absolute limits of detection for desmethylmisonidazole, misonidazole and internal 
standard are 2,3 and $4 \mathrm{pg}$, respectively. Detection limits were determined at a detector sensitivity of $2 \mathrm{nA}$ full scale deflection, a time constant of $0.5 \mathrm{sec}$, a noise equal to $60 \mathrm{pA}$ and an injection volume of $5 \mu \mathrm{l}$. At a signal-to-noise ratio of 2 the limits of quantitation are $1.0 \mu \mathrm{g} / \mathrm{l}$ for desmethylmisonidazole and $1.6 \mu \mathrm{g} / \mathrm{l}$ for misonidazole. If necessary these limits may be lowered by increasing the injection volume or by choosing another procedure, which makes use of solvent extraction. Such extraction procedures have been described for spectrophotometric [15], polarographic [15, 16], TLC [17] and LC-UV [28] procedures for misonidazole and desmethylmisonidazole in biological fluids.

Electrochemical detection versus UV absorbance detection

Comparative detection limits for electrochemical detection at $-0.60 \mathrm{~V}$ and UV absorbance detection at $323 \mathrm{~nm}$ are given in Table I. For the studied nitroimidazoles the detection limits determined at a signal-to-noise ratio of 2 were $10-20$ times lower using electrochemical detection at $-0.60 \mathrm{~V}$ than those obtained with UV detection at $323 \mathrm{~nm}$ being the wavelength of maximal absorbance.

\section{TABLE I}

DETECTION LIMITS OF NITROIMIDAZOLES WITH ELECTROCHEMICAL AND UV ABSORBANCE DETECTION

Nitroimidazole Detection limit ${ }^{\star}(\mathrm{pg})$

$$
\begin{array}{ll}
\text { Electrochemical detection } & \text { UV absorbance detection } \\
\text { at }-0.60 \mathrm{~V} & \text { at } 323 \mathrm{~nm}
\end{array}
$$

$\begin{array}{lll}\text { Desmethylmisonidazole } & 2 & 35 \\ \text { Misonidazole } & 3 & 50 \\ \text { Internal standard } & 4 & 55\end{array}$

^ Determined at a signal-to-noise ratio of 2.

\section{Clinical application}

Chromatograms of plasma samples of a patient before and $24 \mathrm{~h}$ after oral intake of $2.85 \mathrm{~g} / \mathrm{m}^{2}$ misonidazole are shown in Fig. 3. Using the described procedure we were able to study the pharmacokinetics of nitroimidazoles in patients undergoing radiation therapy of tumours. Results of these studies will be published soon.

\section{Other nitro compounds}

This technique also proved to be applicable to the sensitive electrochemical detection of other nitroimidazoles such as 2-nitroimidazole, metronidazole, nimorazole and tinidazole and nitro compounds such as nitrofurantoin. Under the conditions of this method these compounds eluted as sharp and symmetrical peaks with retention times between 2.7 and $5.9 \mathrm{~min}$. For 100 pmol injected compound the current response at $-0.60 \mathrm{~V}$ ranged between 8 and $10 \mathrm{nA}$ for the 5-nitroimidazole drugs and nitrofurantoin, while the response for the 2-nitroimidazole compounds varied from 16 to $28 \mathrm{nA}$. 


\section{ACKNOWLEDGEMENT}

The authors gratefully acknowledge the support of the Lutgerdina Bouwman Foundation for Cancer Research (The Netherlands).

\section{REFERENCES}

1 J. Denekamp and S.R. Harris, Radiat. Res., 61 (1975) 191.

2 J. Denekamp and J.F. Fowler, Int. J. Radiat. Oncol. Biol. Phys., 4 (1978) 143.

3 R.H. Thomlinson and L.H. Gray, Brit. J. Cancer, 9 (1955) 539.

4 J. Denekamp, J.F. Fowler and S. Dische, Int. J. Radiat. Oncol, Biol. Phys., 2 (1977) 1227.

5 G.E. Adams, Int. J. Radiat. Oncol. Biol. Phys., 4 (1978) 135.

6 L.H. Gray, A.O. Conger, M. Ebert, S. Hornsey and O.C.A. Scott, Brit. J. Radiol., 26 (1953) 638 .

7 S. Dische, M.I. Saunders, I.R. Flockhart, M.E. Lee and P. Anderson, Int. J. Radiat. Oncol. Biol. Phys., 5 (1979) 851.

8 J.F. Fowler and J. Denekamp, Pharmacol. Ther., 7 (1979) 413.

9 R.C. Urtasun, P. Band, J.D. Chapman, H.R. Rabin, A.F. Wilson and C.G. Fryer, Radiology, $122(1977) 801$.

10 K. Jentzsch, K.H. Kärcher, H.D. Kogelnik, E. Maida, B. Mamoli, P. Wessely, F. Zaunbauer and V. Nitsche, Strahlentherapie, 153 (1977) 825.

11 S. Dische, M.I. Saunders, M.E. Lee, G.E. Adams and I.R. Flockhart, Brit. J. Cancer, 35 (1977) 567.

12 M.I. Saunders, S. Dische, P. Anderson and I.R. Flockhart, Brit. J. Cancer, 37 (Suppl. III) (1978) 268.

13 J.L. Foster, I.R. Flockhart, S. Dische, A. Gray, I. Lenox-Smith and C.E. Smithen, Brit. J. Cancer, 31 (1975) 679.

14 I.R. Flockhart, P. Large, D. Troup, S.L. Malcolm and T.R. Marten, Xenobiotica, 8 (1978) 97.

15 J.A.F. de Silva, N. Munno and N. Strojny, J. Pharm. Sci., 59 (1970) 201.

16 M.A. Brooks, L. d'Arconte and J.A.F. de Silva, J. Pharm. Sci., 65 (1976) 112.

17 D. Tonelli, E. Gattavecchia and A. Breccia, J. Chromatogr., 275 (1983) 223.

18 E. Gattavecchia, D. Tonelli and A. Breccia, J. Chromatogr., 224 (1981) 465.

19 P. Workman, C.J. Little, T.R. Marten, A.D. Dale, R.J. Ruane, I.R. Flockhart and N.M. Bleehen, J. Chromatogr., 145 (1978) 507.

20 P.G. Meering and R.A.A. Maes, J. Chromatogr., 225 (1981) 407.

21 R.W. Hubbard and F.A. Beierle, J. Chromatogr., 232 (1982) 443.

22 A.J. Varghese, Anal. Biochem., 110 (1981) 197.

23 L. Roizin-Towle, L. Roizin, E.J. Hall and J.C. Liu, in L.W. Brady (Editor), Radiation Sensitizers, Mason, New York, 1980, p. 444.

24 A.J. Varghese and G.F. Whitemore, Chem. Biol. Interact., 36 (1981) 141.

25 J.B. Chin, D.M.K. Sheinin and A.M. Rauth, Mutat. Res., 58 (1978) 1.

26 P. Zuman, in P. Zuman, L. Meites and I.M. Kolthoff (Editors), Progress in Polarography, Vol. 3, Wiley, New York, 1972, p. 73.

27 K. Bratin and P.T. Kissinger, J. Liquid Chromatogr., 4 (Suppl. 2) (1981) 321.

28 G.A. Gudauskas, B. Palcic and S. Kong, Clin. Biochem., 11 (1978) P-8. 